Original article

\title{
An insight into effectiveness and potential damage in removing limewash from wall paintings. An approach based on model samples
}

\author{
Carmen Canevali ${ }^{\mathrm{a}, *}$, Mariarosa Lanfranchi ${ }^{\mathrm{b}, \mathrm{g}}$, Harpreet Tanday ${ }^{\mathrm{b}, \mathrm{h}}$, Cristina Cortic, \\ Damiano Monticelli ${ }^{\mathrm{d}}$, Laura Rampazzi ${ }^{\mathrm{c}, \mathrm{f}}$, Moira Bertasa ${ }^{\mathrm{e}, \mathrm{i}}$, Antonio Sansonetti ${ }^{\mathrm{f}, *}$ \\ ${ }^{a}$ Department of Materials Science, University of Milano-Bicocca, Via Roberto Cozzi 55, Milan, Italy \\ b Scuola Universitaria della Svizzera Italiana (SUPSI), Campus Mendrisio, Via Catenazzi 23, Mendrisio, Switzerland \\ ${ }^{\mathrm{C}}$ Department of Human Sciences and Innovation for the Territory, Università degli Studi dell'Insubria, Via Sant'Abbondio 12, Como, Italy \\ ${ }^{\mathrm{d}}$ Department of Science and High Technology, Università degli Studi dell'Insubria, Via Valleggio 11, Como, Italy \\ e Department of Chemistry and NIS Centre, University of Turin, Via Pietro Giuria 7, Turin, Italy \\ ${ }^{\mathrm{f}}$ Institute for Heritage Science (ISPC), National Research Council (CNR), Via Roberto Cozzi 53, Milan, Italy \\ ${ }^{g}$ Opificio delle Pietre Dure, Via degli Alfani 78, 50122 Firenze, Italy

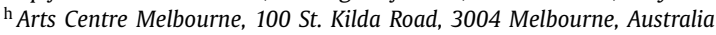 \\ i Department of Scientific Research, The British Museum, Great Russell Street, London WC1B 3DG, United Kingdom
}

\section{A R T I C L E I N F O}

\section{Article history:}

Received 10 May 2021

Accepted 5 August 2021

\section{Keywords:}

Cleaning

Wall paintings

Agar gel

Cellulose pulp

Limewash

Hematite

\begin{abstract}
A B S T R A C T
The mechanism, the effectiveness, and the potential damage during limewash removal from wall painting models were evaluated for agar gels and water-based pads constituted by Arbocel ${ }^{\mathrm{TM}}$ BWW 40 cellulosic fibre. Cleaning materials in different formulations were compared: pure and with additives (ethylenediaminetetraacetic acid, EDTA, and ammonium citrate tribasic, TAC) in different percentages ( $2 \%$ and $3 \%$ ). The cleaning action was evaluated on laboratory model samples, prepared with hematite $a$ fresco and an egg-based tempera with limewash overlayers. Calcium and iron extracted by cleaning materials were quantified by inductively coupled plasma-mass spectrometry (ICP-MS). The potential damage to the hematite painting layers was also studied by electron paramagnetic resonance (EPR) spectroscopy. A visual observation of the limewash detachment induced by the overall cleaning was also performed. Results suggest that limewash removal mainly occurs by aqueous solution release from the cleaning system, with subsequent layer wetting, probable layer swelling, weakening and complete or partial detachment. A stronger limewash adhesion on the hydrophilic fresco surface than on tempera, was observed. None of the used cleaning materials resulted harmful to the integrity of the hematite layer underneath the limewash. A small damage in terms of extracted iron was detected in the cleaning systems after direct contact with fresco and tempera hematite layers; a "protective" effect by the tempera layer was observed for the pigment, due to the organic binder and triggered by the hydrophobic content of the egg-based medium.

Cleaning materials with additives are more harmful than pure materials, with a greater coordinating ability for EDTA than for TAC, which increases with chelator percentage. Data suggest a more efficient backward transportation of aqueous solutions containing calcium and iron ions towards gels with respect to cellulose, due to their smallest pore size. All these results lead to operative suggestions: for fresco painting layers, pure gel allows both a good limewash removal and a lack of damage on the hematite layers. Instead, for tempera layers a good limewash removal and a negligible damage on the pigment was shown by gel, both pure and additivated with TAC, and pure cellulose. Therefore, the present study allows to identify proper characterization methods for evaluating effectiveness and damage in limewash removal and to give useful suggestions for the planning of repeated cleaning operations on a real polychrome object.
\end{abstract}

(ㄷ) 2021 Elsevier Masson SAS. All rights reserved.
* Corresponding authors.

E-mail addresses: carmen.canevali@unimib.it antonio.sansonetti@cnr.it (A. Sansonetti).

\section{Introduction}

Cleaning an artwork surface requires highly effective methodologies, which are respectful of the artefact itself and its constituent materials [1-3]. The cleaning of mural paintings is a good 
example of how particularly delicate this process is, as they generally consist of a complex inorganic/organic matrix requiring the cleaning plan to be tailored to the specific conservation issues. The removal of soil, deposits and inorganic salts, having different water solubilities and often mixed with organic residues, is a typical example of such procedures [4]. Another example is the removal of layers applied on purpose during past works, such as lime whitewash or tempera overpaints, that can even reach thickness in the $\mathrm{mm}$ range. In these cases, the cleaning procedure very often establishes to firstly reduce the layer total thickness by mechanical methods (blades, sponges, brushes), usually after weakening of the layer cohesion with some chemicals to minimize the mechanical impact over the substrate. Then the cleaning is completed by applying a chemical pad directly onto the cleared painted surface. During these operations, the selectivity is of the utmost importance, to ensure that the chosen chemicals are effective at removing the applied layer without damaging the underlying painted ones. Selectivity requirements are usually very high because the whitewash or the overpaints are often similar in composition to the painted layer (e.g., calcite, casein or other organic binders, gypsum, pigments, calcium oxalate or other decay by-products). A difficult issue is represented by painted substrate covered by a whitewash layer; for instance, this implies calcium and iron in the same stratigraphy, few hundreds $\mu \mathrm{m}$ or less distant, and in a semiporous system permeable to the used solutions. Both effectiveness and damage issues may be well assessed making use of model samples designed on purpose, since real samples are not enough homogeneous for such studies. Moreover, the Model Samples approach is planned to represent an overall conservation issue, thus it has already been used to study specific cleaning issues of wall paintings [3,5], marble surfaces [6] and stuccoworks [7].

The selectivity issue is strongly related to the nature of the chemical pad directly applied onto the original surface. Cellulose pulp mixed with water and various chemicals is extensively used by conservators as liquid reservoir and absorbent pad for both stone substrates [8-10] and painted plasters [11]. Pure water or its mixture with polar solvents, such as ethanol and acetone, is normally used. Non-polar solvents are also used in the practice, with the addition of surfactants [11]. However, cellulose pulp pads do not effectively retain the solvents, since their release to the absorbing substrate is a quite fast kinetic mechanism, with limited control on the liquid diffusion [12].

To overcome this drawback, conservators are more and more making use of gels, both synthetic and natural, in the attempt to improve cleaning performances. Synthetic gels include networks formed by both a single type of polymer and semi-interpenetrating polymers showing optimal mechanical properties and retentiveness [13-16]. On the other hand, natural polysaccharide gels are highly effective, versatile, low-cost, and gentle on the artworks [6,17-20]. Among natural polymers, agar gels are currently the most used material by Italian restorers for removing soiling [17] and metal stains from artwork surfaces [18, 21-25].

Both cellulose and gel pads may be implemented by adding chelating agents [26,27], which showed outstanding practice improvements, worth a full investigation. Chelators are already used in the conservation of stone materials, thanks to their effectiveness in removing newly formed calcium compounds, such as black crusts mainly composed of gypsum and calcite, and white calcite thin layers or encrustations [3]. Agar gels with ethylenediaminetetraacetic acid (EDTA) and ammonium citrate tribasic (TAC) were used for the removal of brochantite stains from the marble base of the bronze statue portraying Napoleon by Antonio Canova, located in the Brera Gallery courtyard, Milan (Italy) [28]. On the other hand, the use of EDTA and citrate has been only recently reported for the removal of layers containing calcium salts on wall paintings [3].
For what concerns the selective removal of lime whitewash (hereinafter "limewash"), there is no agreement on which cleaning technique best preserves the coloured underpaintings [29], nor a systematic comparison has been investigated yet between cellulose pads and gels, evaluating their action mechanism, benefits, and limits. Thus, the present paper will study the cleaning mechanism of agar gels and cellulose pulp pads and will compare them in terms of:

a) the effectiveness of limewash removal from painting layers based on hematite, applied with different techniques (a fresco and an egg-based tempera). Hematite was chosen because it is a very common iron-based pigment in mural paintings; moreover iron forms stables complexes with the used chelating agents. $A$ fresco and a tempera layers were chosen in order to evaluate the protecting action of the different binders with respect to the chelating species;

b) the damage on the hematite painting layers underlying the limewash (first step of limewash removal);

c) the potential damage on hematite painting layers when they are directly contacted with the cleaning pads (second step of improving limewash removal).

These objectives were achieved by comparing the cleaning action of different formulations of agar gels and cellulose pulp, both pure and with additives (EDTA and TAC) in different percentages ( $2 \%$ and $3 \%$ ). Cleaning was performed on laboratory model samples under well-controlled and reproducible conditions.

For the evaluation of limewash removal, different techniques were used: colorimetric measurements fail, since the mean colour difference in painting layers is not high enough; on the other hand, hyperspectral imaging techniques gave different results according to the used analysis methods [29]. In the present paper, both the effectiveness of limewash removal and the potential damage to hematite painting layers were evaluated in cleaning materials as extracted calcium and iron, respectively. Metal concentration was quantified by inductively coupled plasma-mass spectrometry (ICPMS). This analytical method allows to obtain quantitative data, useful to compare some aspects of the effectiveness and the damage issues; it was successfully used for the systematic comparison of different agar gel formulations in the removal of brochantite stains from marble surfaces $[6,28]$. A visual observation of the limewash detachment induced by the overall cleaning was also performed, which is the usual type of empirical evaluation made by conservators, in the attempt to link the scientific analytical approach to the practical one. The potential damage to the hematite painting layers was also evaluated by electron paramagnetic resonance (EPR) spectroscopy.

\section{Research aims}

The present paper deals with the cleaning of mural paintings, especially with the removal of layers applied on purpose during past works, such as limewash. In these issues, the selectivity is of the utmost importance, to ensure that the chosen chemicals are effective at removing the applied layer without damaging the underlying painted ones. Thus, the present paper will study the cleaning mechanism of agar gels and cellulose pulp pads, comparing:

a) the effectiveness of limewash removal from painting layers based on hematite, applied with different techniques (a fresco and a tempera);

b) the damage on the hematite painting layers underlying the limewash;

c) the potential damage on hematite painting layers when they are directly in contact with the cleaning pads. 
These objectives were achieved by comparing the cleaning action of different formulations of agar gels and cellulose pulp on laboratory model samples under well-controlled and reproducible conditions.

\section{Materials and methods}

\subsection{Materials}

River sand (granulometry $0.2 \mathrm{~mm}$ ) and lime putty (CTS, $\mathrm{CH}$ ) were used to plaster terracotta tiles supports. Hematite (Dolci Colori srl, Italy), magnesian lime putty (La Banca della Calce s.r.l., Italy), whole milk and ammonium oxalate (Bresciani srl., Italy) were used for limewash preparation. AgarArt powder, Arbocel ${ }^{\mathrm{TM}}$ BWW 40 powdered cellulose, EDTA tetrasodium and triammonium citrate (CTS, $\mathrm{CH}$ ) were used for surface cleaning. $\mathrm{HNO}_{3}$ (70\%, Carlo Erba, Italy) and $\mathrm{H}_{2} \mathrm{SO}_{4}$ (95-98 \%, Sigma Aldrich, Italy), both for analysis grade, were used for cleaning material dissolution. Commercial $1000 \mathrm{mg} / \mathrm{L}$ standards from Fluka (TraceCERT) for iron and from Merck (CertiPUR) for calcium were used for ICP-MS calibration. Ultrapure water, produced by a Sartorius Arium Mini System, was used when necessary.

\subsection{Model sample preparation}

Three types of model samples, fresco, tempera and limewash, were prepared as follows: eight terracotta tiles $(8 \times 10 \mathrm{~cm})$ were coated with $1 \mathrm{~cm}$ thick lime plaster (lime putty/quartz sand 1:3 $\mathrm{w} / \mathrm{w})$. All of them were fully painted with hematite, but four of these were painted a fresco (Fig. 1a) and the remaining four were painted a tempera (Fig. 1b). Eventually, limewash was applied over the half of the hematite painted surfaces (Fig. 1c and 1d).

\subsubsection{Model samples with hematite}

As regards the red painted surfaces, hematite was milled, washed 3 times in ultrapure water, decanted and mixed with the media as follows. For fresco model samples, hematite was dispersed in ultrapure water, then was applied on the intonachino with three parallel brushstrokes in order to get the most homogeneous layer possible. For tempera model samples, egg-based binder was prepared accordingly to the medieval tradition reported in the literature [30]. Then, the pigment was added $(1 / 1 \mathrm{v} / \mathrm{v})$. Once ready, tempera model samples were aged for 60 days at $26^{\circ} \mathrm{C}$ and R.H. 64 $\%$, then for 20 days at $40^{\circ} \mathrm{C}$ and $64 \%$ R.H. Painting film thickness resulted $150 \pm 30 \mu \mathrm{m}$ for both fresco and tempera, as estimated by SEM images (section 3.3).
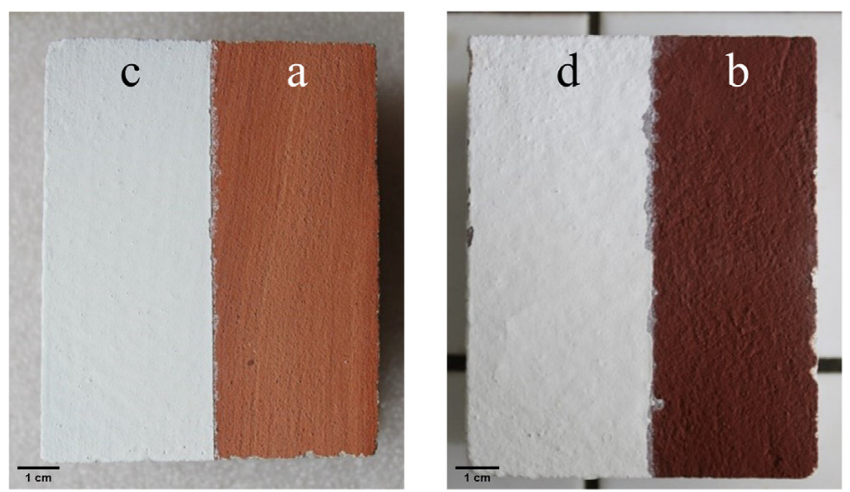

Fig. 1.. Fresco (a) and tempera (b) hematite layers, with limewash (c and d, respectively). Total size of each tile $8 \times 10 \mathrm{~cm}$.

\subsubsection{Limewash on model samples}

Limewash was prepared as follows: magnesian lime putty (40\% $\mathrm{w} / \mathrm{w})$, whole milk $(10 \% \mathrm{w} / \mathrm{w})$, and ammonium oxalate $(3 \% \mathrm{w} / \mathrm{w})$ were dispersed in ultrapure water. The oxalate salt and the milk were added to induce the presence of calcium oxalate in the final layer and to reproduce a common real limewash, where very often calcium oxalates are formed due to the degradative oxidation of organic additives and treatments or to the metabolic activity of microorganisms [31]. The mixture was allowed to set for 5 days, during which regular stirring assured a uniform dispersion. Then, limewash was applied by means of an airbrush perpendicularly used over the models laying horizontally and at a constant distance (around 80-90 cm). Limewash was sprayed twice for 7 seconds at a working pressure of 4 bars, with a 20-min interval between the two sprayings. At the end of the application, limewash looked flat, uniform and sound. Model samples were kept in air (temperature $=7-12^{\circ} \mathrm{C}$; R.H. $=55-80 \%$ ) for 6 months, allowing them to reach complete carbonation.

Limewash thickness resulted to be $208 \pm 50 \mu \mathrm{m}$, as estimated by SEM images (section 3.3).

\subsection{Model sample characterization}

The photographic images were performed using a Canon EOS 1300D DSLR with 18-55mm lens, 18-megapixel APS-C size sensor and the DIGIC $4+$ image processor.

Scanning electron microscopy (SEM) images allowed to estimate the layer thickness as the average of 20 observations. Cross-section images were taken from the central area of the model samples on a JEOL 5910LV microscope (IXRF Systems). Images were acquired in backscattered mode, using a beam current of $1-3 \times 10^{-7} \mathrm{~A}$.

Infrared spectra were recorded using a Jasco 4100 Fourier Transform Infrared spectrophotometer, in attenuated total reflectance mode (FTIR-ATR, spectral range 4000 and $600 \mathrm{~cm}^{-1}$, resolution $4 \mathrm{~cm}^{-1}$ ). Powders were collected by means of a scalpel from the centre of the models, in an area not interested by the cleaning trials.

X-ray Diffractions (XRD) were carried out on powdered samples collected as for FTIR-ATR and placed on silicon wafer (zero background). Diffractograms were recorded in the range $3^{\circ}-75^{\circ}$ $2 \vartheta$ on a Panalytical X'Pert PRO with geometry goniometer $\vartheta-\vartheta$, with scanning velocity $0,21^{\circ} / \mathrm{sec}$, using a $\mathrm{Cu} \mathrm{K} \alpha$ radiation, a PW 3040/60 generator with condition $40 \mathrm{KV}$ (tube) and $40 \mathrm{~mA}$ (current of filament), with a solid state multi-detector X'Celerator PW3015/20 with a Ni filter. Analyses were carried out with 1 and $1 / 2$ slits referring to Anti-scatter slit and divergence slit and Mask $\mathrm{n}^{\circ} 15$.

\subsection{Cleaning materials preparation and cleaning procedure}

Cleaning materials were identified with codes reported in Table 1.

Agar gels were prepared dissolving $3 \mathrm{~g}$ of agar raw powder in $100 \mathrm{ml}$ of ultrapure water (Agar 3\%). Gels were prepared both pure

Table 1

Cleaning materials in different formulations with related codes and $\mathrm{pH}$ values.

\begin{tabular}{lll}
\hline Cleaning materials & Codes & pH \\
\hline Gel & G & 6 \\
Gel-EDTA 2 $\%$ & GE2 & 12 \\
Gel-EDTA 3\% & GE3 & 11 \\
Gel-TAC 2 \% & GT2 & 7 \\
Gel-TAC 3 \% & GT3 & 7 \\
Cellulose & C & 7 \\
Cellulose-EDTA 3 \% & CE3 & 12 \\
Cellulose-TAC 3 \% & CT3 & 7 \\
\hline
\end{tabular}



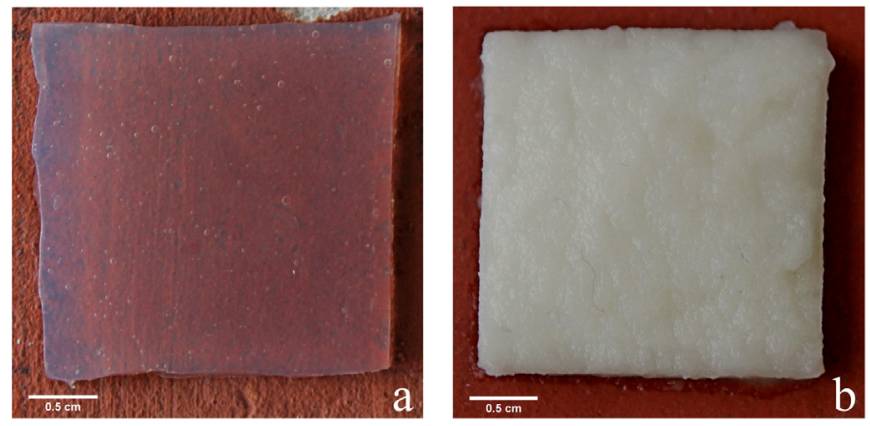

Fig. 2.. Pure agar gel on fresco (a) and pure cellulose pad on tempera (b).

(G) and with additives (EDTA and TAC). In the latter case, additives were mixed at 2\% w/w (GE2 and GT2, respectively) and 3\% w/w (GE3 and GT3, respectively), with respect to the agar aqueous solution.

Hence the mixes were heated to $95^{\circ} \mathrm{C}$, then cooled to room temperature. This procedure was repeated twice to get transparent gels. The warm solutions (around $50^{\circ} \mathrm{C}$ ) were poured in Petri capsule $(\varnothing=115 \mathrm{~mm})$ up to $0.5 \mathrm{~cm}$ thickness. Once cooled, pads sized $2.5 \times 2.5 \times 0.5 \mathrm{~cm}$ were cut to fit the area of the model sample to be treated.

Cellulose pads were prepared with cellulose powder Arbocel ${ }^{\mathrm{TM}}$ BWW40, which exhibits the highest specific surface area among similar products on the market, due to its limited fibres length (200 $\mu \mathrm{m})$. Ultrapure water was added to achieve a cellulose:water $0.25 \mathrm{w} / \mathrm{w}$ ratio. Cellulose pads were prepared both pure (C) and with additives (EDTA or TAC, $3 \% \mathrm{w} / \mathrm{w}$; CE3 and $\mathrm{CT} 3$, respectively), in rigid plastic frames sized exactly as the cut gels $(2.5 \times 2.5 \times 0.5 \mathrm{~cm})$. The pads were prepared by filling the frames with a spatula; the quantity of cellulose pulp contained in each frame was measured (3.75 $\mathrm{g} \pm 7 \%$ ).

Both gels and cellulose pulps were applied directly on model surfaces. All cleaning systems were applied horizontally (Fig. 2) and they were kept in contact with model samples for $60 \mathrm{~min}$, then they were removed. Small residues of detached limewash were mechanically removed with a scalpel. Care was taken in order to carry out removal operations in a reproducible manner and to avoid visible damage to the underneath red layers.

\subsection{Characterization of the cleaning materials}

The $\mathrm{pH}$ values of cleaning materials (gels and cellulose pulp) were measured by paper $\mathrm{pH}$ indicators contacted with the surfaces (Table 1).

$\mathrm{Ca}$ and Fe concentrations in the cleaning materials were determined by ICP-MS. The metal solutions for analysis were prepared as follows. After contact with model samples, cleaning materials $(2.5 \times 2.5 \times 0.5 \mathrm{~cm})$ were removed, weighed, dissolved in a sulfonitric $\left(\mathrm{HNO}_{3}: \mathrm{H}_{2} \mathrm{SO}_{4}=1: 3\right)$ solution, then diluted with ultrapure water. Mixed iron-calcium standard solutions were prepared and diluted with ultrapure water. All the samples and standard solutions were added with ultrapure nitric acid to a final concentration of $2 \% \mathrm{w} / \mathrm{w}$. Nitric acid was produced by sub-boiling distillation with a DuoPUR-Milestone equipment [32].

$\mathrm{Ca}$ and Fe concentrations were determined by ICP-MS (Thermo Elemental iCAPQ) using the kinetic energy discrimination configuration to allow iron determination. External calibration was used for quantification using the ${ }^{43} \mathrm{Ca}$ and ${ }^{56} \mathrm{Fe}$ isotopes. Procedural blanks and control standards were also analysed during each analysis batch. Data were normalized according to each sample weight. Typical relative percentage standard deviations (RSD\%) of the analyte concentrations were $2 \%$.

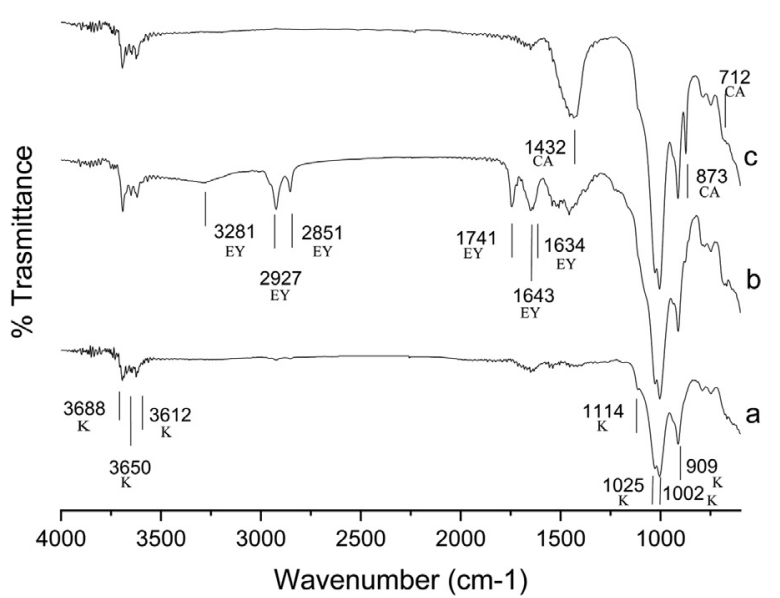

Fig. 3.. FTIR-ATR spectra of (a) hematite with peaks of kaolinite (k), (b) tempera with peaks of calcite (CA) and of proteinaceous materials present in egg yolk (EY) and (c) fresco with peaks of calcite (CA).

$\mathrm{Fe}(\mathrm{III})$ was selectively characterized by EPR in cleaning materials (agar gels and cellulose pulps) after application onto model samples. An aliquot of each cleaning material was inserted into a quartz tube ( $3 \mathrm{~mm}$ internal diameter) and pushed towards its bottom by a Teflon rod. EPR spectra were recorded at $123 \mathrm{~K}$ with a Bruker EMX spectrometer working at the X-band frequency, equipped with a variable temperature BVT 2000 unit, using a microwave power of $5 \mathrm{~mW}$, a modulation amplitude of $5.0 \mathrm{G}$, and a modulation frequency of $100.0 \mathrm{kHz}$. The g values were determined by standardization with $\alpha, \alpha^{\prime}$-diphenyl- $\beta$-picryl hydrazyl (DPPH) radical. Since it was not possible to compact materials at the bottom of the EPR tubes, any quantitative comparison among different samples was avoided.

\section{Results and discussion}

All model samples as prepared were characterized by FTIR-ATR and XRD, to verify whether the selected materials and the preparation procedure worked properly to mirror a real limewash. Then, its removal effectiveness was estimated by quantifying the calcium content in cleaning materials (ICP-MS analyses) after a controlled 60 min contact with the model samples and by visually inspecting model samples (photographic images). Furthermore, the potential damage to the hematite painting layers, both $a$ fresco and a tempera, was studied through the assessment of the iron content and of the hosted iron centres coordination by ICP-MS and EPR spectroscopy, respectively.

\subsection{Characterization of model samples as prepared}

\subsubsection{Model samples with hematite}

The FTIR-ATR spectrum of the red pigment (Fig. 3a) reported the peaks corresponding to kaolinite, $\mathrm{Al}_{2} \mathrm{O}_{3} \cdot 2 \mathrm{SiO}_{2} \cdot 2 \mathrm{H}_{2} \mathrm{O}$ (outer and inner hydroxyl ions stretching at 3688, 3650 and $3612 \mathrm{~cm}^{-1}$; Si-O stretching bands at 1114, 1025 and $1002 \mathrm{~cm}^{-1}$; O-H deformation at $909 \mathrm{~cm}^{-1}$ ), present as a natural component [33]. Both model samples tempera (Fig. 3b) and fresco (Fig. 3c) show the peaks of calcium carbonate, in the mineralogic form of calcite, due to the support (C-O asymmetric stretching band at $1432 \mathrm{~cm}^{-1}$, out-of-plane bending vibration at $873 \mathrm{~cm}^{-1}$ and in-plane bending signal at $712 \mathrm{~cm}^{-1}$ ), which are more intense in fresco than in tempera, as expected since carbonate is the binder in fresco [34,35]. As regards tempera sample (Fig. $3 \mathrm{~b}$ ), the characteristic peaks of proteinaceous materials of the egg yolk are observable as well, in particular the shoulder assigned to the stretching of the $\mathrm{NH}$ amide 


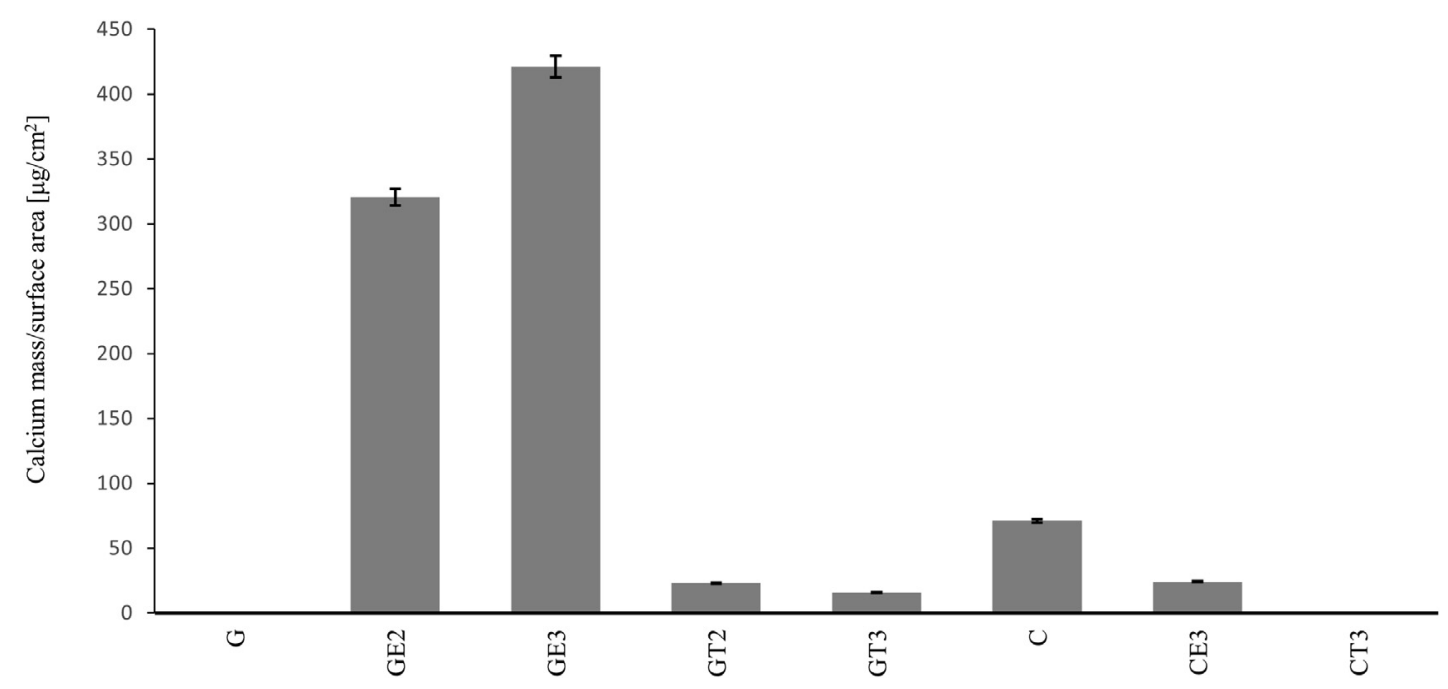

Fig. 4.. Calcium content per surface area, determined in the cleaning materials by ICP-MS after 60 min contact with limewash model samples.

group (3281 $\left.\mathrm{cm}^{-1}\right)$, the stretching of the $\mathrm{CH}_{2}$ group (2927 and $2851 \mathrm{~cm}^{-1}$ ), the peak of the ester carbonyl of triglycerides (1741 $\mathrm{cm}^{-1}$ ), a doublet attributable to both the carbonyl and the $\mathrm{NH}$ bending of the protein amide group (1643 and $1634 \mathrm{~cm}^{-1}$ ) [36].

\subsubsection{Model samples with limewash}

The FTIR-ATR peaks of calcium carbonate, in the mineralogic form of calcite $\left(1432,873\right.$ and $\left.712 \mathrm{~cm}^{-1}\right)$ and of calcium oxalate (C-O stretching vibration at 1640 and $1329 \mathrm{~cm}^{-1}, \mathrm{O}-\mathrm{C}-\mathrm{O}$ bending vibration at $781 \mathrm{~cm}^{-1}$ ) were observed in these samples [37]. The presence of calcium oxalate into limewash mixture has already been observed in several case studies [31] and it might contribute to the overall cohesion of the limewash. The chemical availability of calcium with respect to chelation is influenced by the presence of this compound, which is characterized by a very low water solubility compared to the other components. In fact, calcium oxalate has a $\mathrm{K}_{\mathrm{sp}} 1.38 \times 10^{-8}$, less than one order of magnitude lower than that of calcium carbonate $9.33 \times 10^{-8}$ [38].

The presence of calcium oxalate as weddellite was confirmed by X-ray diffraction (XRD) analysis.

Thus, the success in replicating a real limewash, which includes calcium oxalate, was proven.

\subsection{Evaluation of limewash removal effectiveness}

\subsubsection{ICP-MS analyses of cleaning materials}

The ICP-MS analyses of the calcium content in cleaning materials are reported in Fig. 4. Calcium content removed by cleaning materials without chelating agents is negligible. Moreover, no significant differences between fresco and tempera model samples coated with limewash were observed (data not shown); this result suggests that the calcium content is not affected by the type of painting layer under the $208 \mu \mathrm{m}$ thick limewash.

The highest calcium removal was obtained with GE3, with a calcium concentration of $420 \mu \mathrm{g} / \mathrm{cm}^{2}$, corresponding to the 2 $\%$ of the calculated calcium concentration in limewash layer volume $\left(2 \times 10^{4} \mu \mathrm{g} / \mathrm{cm}^{2}\right)$, assumed as formed by calcite only. Besides GE3, only GE2 showed a rather high calcium removal, followed by cleaning materials in this order: $\mathrm{C}>\mathrm{GT} 2 \sim$ GT3 $\sim$ CE3. No calcium removal was detected with $G$ and CT3. These results show that cleaning materials remove a higher calcium concentration with EDTA than with TAC and by far than pure materials, in agreement with the calcium complex stability constants $\left(\log \mathrm{K}_{\mathrm{f}}\right.$ for $\mathrm{EDTA}=10.7$ [39]; for $\mathrm{TAC}=3.5[40]$ ) and the literature $[3,28]$.
Moreover, calcium concentration in gel increases with the percentage of the additive, being higher with additive at $3 \%$ than at 2 $\%$.

Additivated gels remove by far more calcium than corresponding cellulose. This result could be rationalized by considering the two main steps of the metal removal mechanism: 1) release of the water solution containing the chelating agent from the cleaning pad to the substrate and dissolution of the salt by chelation; 2) backward transportation of the aqueous solutions containing the chelated ions from the substrate to the pad. The second step is possibly sustained by diffusion due to the concentration gradient [28] and to the capillary suction mechanism [12]. Gels and cellulose pulps have different chemical and three-dimensional structures as the agar gel chains are arranged in a double helix through hydrogen bonds [41], while the glucose chains in cellulose pulp are arranged in parallel into a single fibre. The single fibres of cellulose are compacted as a function of the pressure exerted by the conservator, when the pad is applied; the inter-fibres cellulose pad porosity may depend on this pressure. On the contrary, the microporosity structure of the gel is due to the gelation mechanisms. We can suppose that gels have smaller pores than cellulose pulp and they retain water more strongly [28], allowing both a slower release to the substrate and a more efficient backward transportation by capillary suction [12].

In general, $\mathrm{pH}$ values are important parameters for metal complex stabilities. However, in the present case no direct correlation was found between calcium removal and the cleaning material $\mathrm{pH}$ values (Table 1 ), probably because they are higher than the threshold values required for Ca-complex stability, being $\mathrm{pH}>8$ for EDTA and $>6$ for TAC, as evaluated by the $\mathrm{pK}_{\mathrm{a}}$ values of the ligands.

After contact with limewash, no iron was detected in any cleaning material. This result shows that the limewash thickness provides an efficient barrier against the action of the tested cleaning agents, which are not harmful towards the painting layer underlying the limewash.

\subsubsection{Overall evaluation of limewash removal}

The limewash removal after contact with the cleaning materials was evaluated by photographic images (Fig. 5). The edges between the treated and the untreated areas appear quite sharp because small residues of detached limewash were mechanically removed with a scalpel, according to a widespread procedure [29].

Only a limited number of the cleaning systems showed an overall good removal effectiveness. Pure gel only was able to detach 

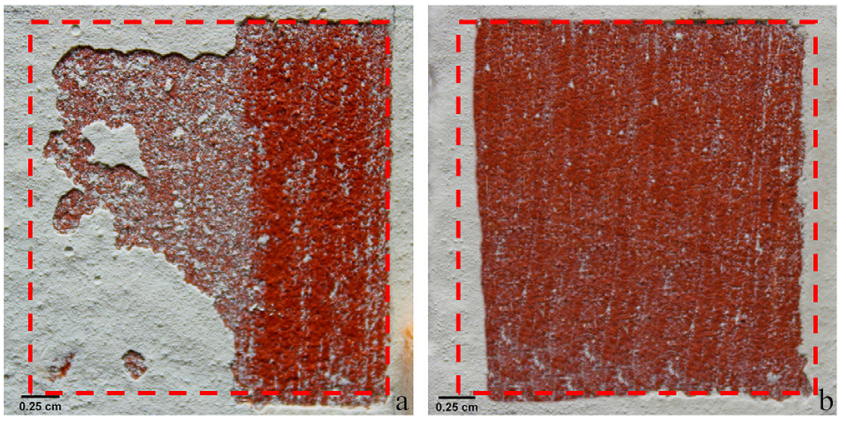

Fig. 5.. Photographic images of limewash on fresco after contact with G (a); limewash on tempera after contact with GE2 (b). In both cases, mechanical removal of residues was made. The side of the dotted square is $2.5 \mathrm{~cm}$.

limewash from fresco, with a modest effectiveness (Fig. 5a). Instead, good limewash removal from tempera was obtained with G, GE2 (Fig. 5b), GE3, GT3 and C, with no significant differences among these cases. Thus, better results for the overall removal of limewash were achieved on tempera than on fresco model samples. This result shows that limewash is more adherent on hydrophilic fresco model samples, even if weakened by the action of cleaning materials. Thus, pure gel can be proposed as a good cleaning material for the limewash removal both from fresco and tempera layers, in agreement with the limewash removal from other tempera layers based on malachite and cinnabar [29]. Hence, the herereported results can have a general value, even if a different adhesion of limewash on underlying layers can be present in different model samples and in real cases. It is also interesting to notice that these results are not fully correlated with the extracted calcium concentration, that was significant for pad GE2 and GE3 only.

Accordingly, data suggest the occurrence of two different and contemporary mechanisms for limewash weakening. They both start with the release of a water solution from the cleaning material to the substrate. Then, they follow two different routes:

1 calcium coordination and extraction from the substrate, as detected by ICP-MS [28];

2 wetting, probable layer swelling, weakening and complete or partial detachment of limewash. This mechanism is not necessarily accompanied by calcium extraction from the substrate.

Data suggest that limewash removal mainly occurs by the latter mechanism.

\subsection{Evaluation of potential damage to hematite layers}

\subsubsection{ICP-MS analyses of cleaning materials}

Iron concentrations, evaluated by ICP-MS analysis, were $\leq 1.4$ $\mu \mathrm{g} / \mathrm{cm}^{2}$ in all cleaning materials, as shown in Fig. 6 and 7. Such a value is about the $2 \times 10^{-3} \%$ of the calculated iron concentration in the red layer $\left(6 \times 10^{4} \mu \mathrm{g} / \mathrm{cm}^{2}\right)$, assumed as formed only by hematite. Thus, only a small iron removal from the hematite painting layer was detected. However, some interesting trends can be further highlighted about this removal.

Iron removal from fresco was observed only by gels with additives, with the highest concentration extracted by GE3 $(1.4 \mu \mathrm{g}$ $\left(\mathrm{cm}^{2}\right)$, followed by GE2 > GT3 > GT2. No iron removal was observed using pure gel and cellulose, the latter in both formulations pure and with additives. Instead, the removal of iron from tempera layers was detected after contact with both gels and cellulose pulps, with maximum values after treatment with CE3 (iron concentration $\left.1.1 \mu \mathrm{g} / \mathrm{cm}^{2}\right)$, followed by GE3 $>$ GT3 $>\mathrm{C} \sim \mathrm{CT} 3$. No iron removal was observed using pure gel.

The most efficient iron removal by gels could be due to their peculiar chemical and three-dimensional structure, as already outlined for calcium removal [12]. Moreover, gels are more harmful on fresco model samples, while cellulose pulp pads are more harmful on tempera models. Structure differences between gels and pulps can lead to a different interaction strength with the underlying layers, which deserves to be investigated in future activity.

It was confirmed that cleaning materials remove a higher iron content when added with EDTA than with TAC, as previously observed also for calcium removal. This is also in agreement with the iron complex stability constants $\left(\log \mathrm{K}_{\mathrm{f}}\right.$ for EDTA $=25.1$ [39]; for $\mathrm{TAC}=11.2[40])$ and the literature $[3,28]$. It is important to notice that a negligible damage was observed after contact with pure cleaning systems on both tempera and fresco layers.

Iron removed from fresco (Fig. 6) is significantly higher than that removed from tempera (Fig. 7). This result is probably related to a minor embedding of iron by the calcium-magnesium matrix of fresco compared to the organic matrix in tempera, which is more effective in protecting iron against the action of chelating agents. The protective effect could be triggered by the hydrophobic content of the egg based medium (lipidic fraction), which hinders the possibility of water to interact with the pigment particles. The protective effect provided by organic binders towards metal ions present in the pigment agrees with the general pigment sensitivity to chemical environment and different pollutants [42]. The sensitivity of pigments embedded in different media (organic and partly

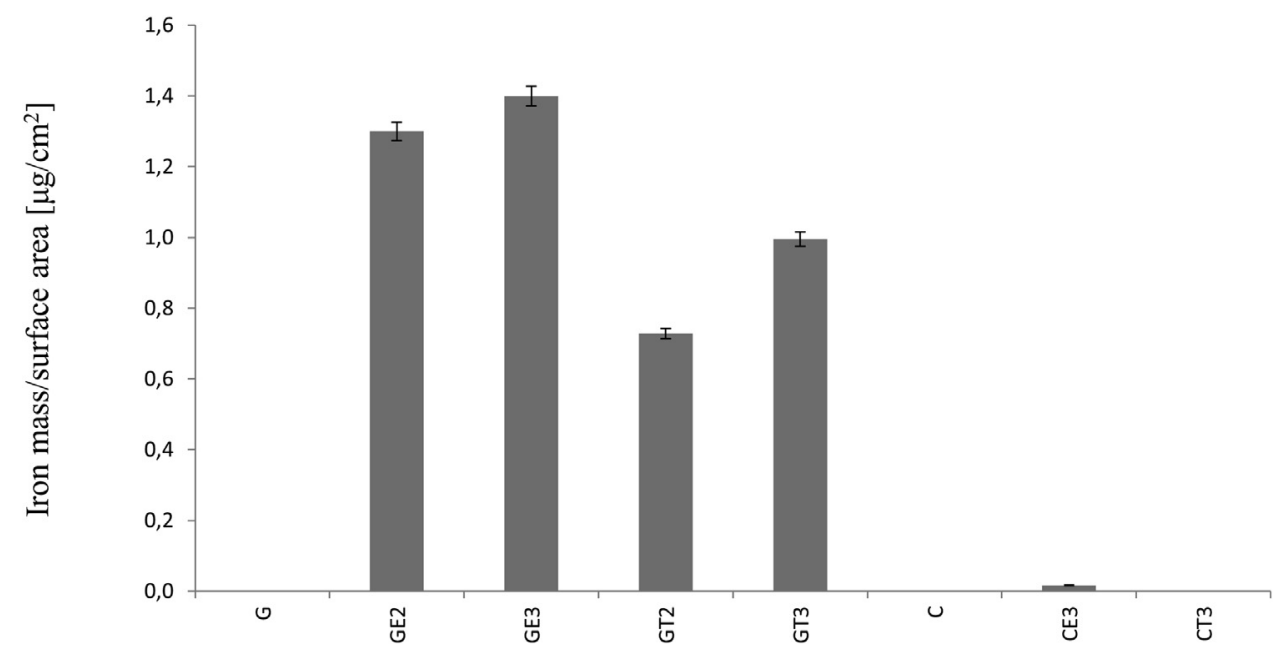

Fig. 6.. Iron content per surface area, determined in the cleaning materials by ICP-MS after 60 min contact with fresco model samples. 


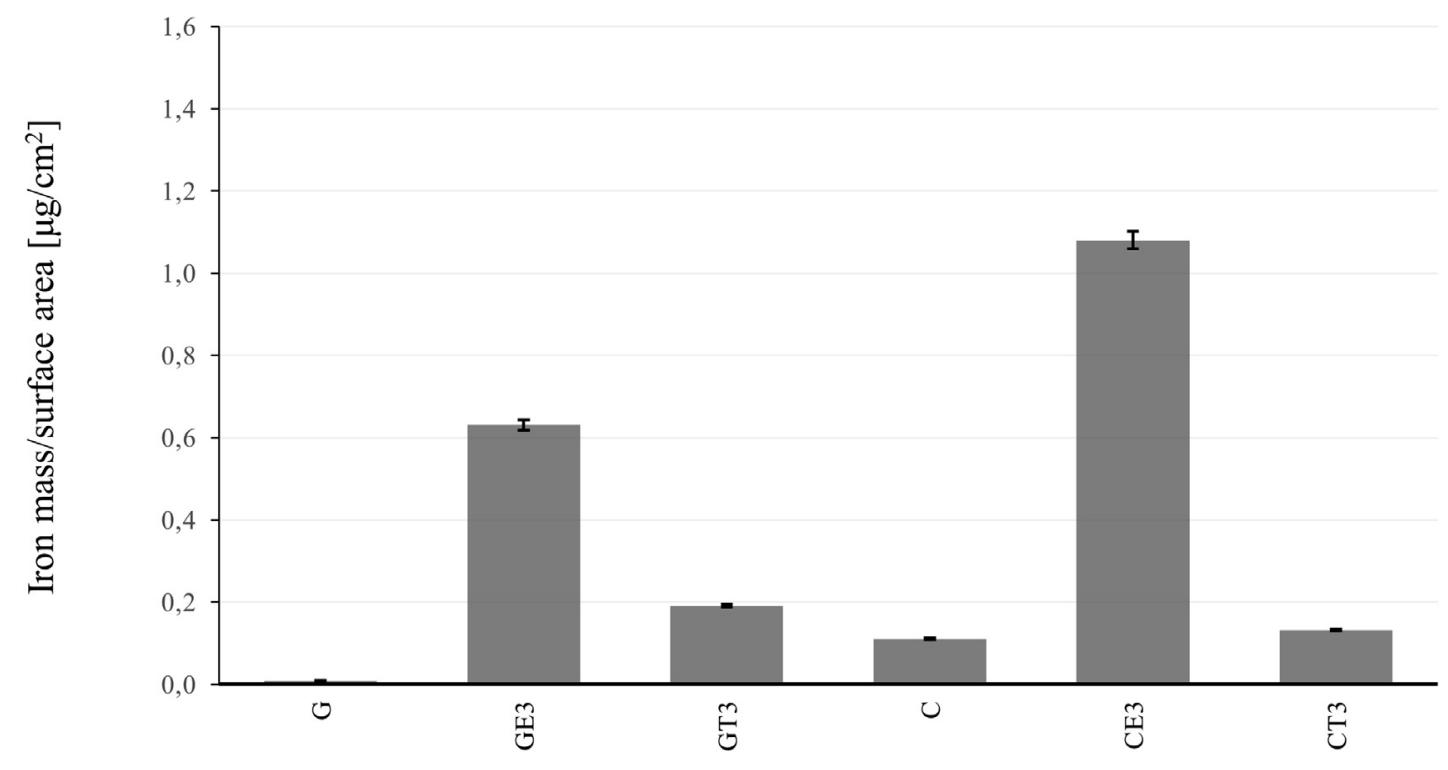

Fig. 7.. Iron content per surface area, determined in the cleaning materials by ICP-MS after 60 min contact with tempera model samples.

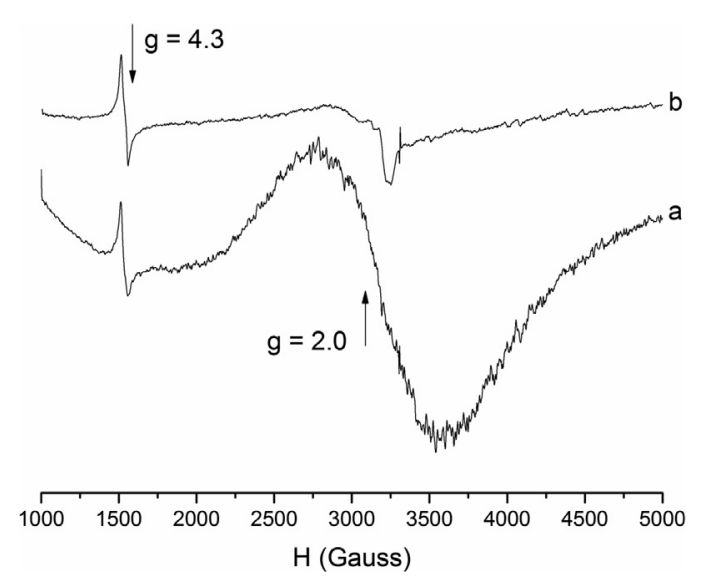

Fig. 8.. EPR spectra at $123 \mathrm{~K}$ of GT3 (a) and GE3 (b) after contact with fresco model samples.

hydrophobic/inorganic) to chelating agents is here reported for the first time, to the best of our knowledge.

No direct correlation was found between the $\mathrm{pH}$ values of the cleaning materials (Table 1 ) and the metal removal, as also reported for calcium. Such lack of correlation is probably due to the quantitative binding of iron by EDTA and TAC at pH higher than 2 [40].

\subsubsection{EPR characterization of cleaning materials}

In order to further evaluate the different iron coordination by EDTA and TAC, the EPR spectra of gels and cellulose pulps were recorded at $123 \mathrm{~K}$ after contact with fresco and tempera model samples.

Since it was not possible to compact cleaning materials at the bottom of the EPR tubes, any quantitative comparison between different samples was avoided. For the same reason, spectra of cellulose pulps showed very low signal to noise ratios and no trend could be observed.

Gel spectra exhibit negligible EPR signals before contact with all model samples and no change was observed even after contacting with the pure gels. On the contrary, the spectra of gels with additives show the presence of $\mathrm{Fe}(\mathrm{III})$ signals attributable to two types of coordination [43]: i) "isolated" iron centres, coordinated by chelating agents or by the cleaning matrix, responsible for the isotropic sharp signal at $\mathrm{g}=4.3$;

ii) "aggregated" iron centres, attributable to Fe(III) aquo-ions, responsible for the isotropic broad signal at $\mathrm{g}=2.0$.

The EPR spectra of gels with TAC show a very strong signal assigned to "aggregated" iron centres (Fig. 8a), together with a smaller signal attributed to "isolated" ones. Conversely, only the signals ascribable to "isolated" iron centres were observed for gels with EDTA (Fig. 8b).

These results confirm that gels with additives are more effective than pure ones in coordinating iron and that the greater harmfulness of the cleaning materials with EDTA is due to its higher coordinating ability with respect to TAC.

\section{Conclusion}

The present paper focusses on the mechanism of gel and cellulose pulp in wall painting cleaning, comparing their effectiveness and damage effects. Model samples mirroring fresco and tempera hematite paints with limewash overlayers were prepared and contacted with agar gels and Arbocel ${ }^{\mathrm{TM}}$ BWW 40 cellulosic pulps in different formulations.

Limewash removal mainly occurs by aqueous solution release from the cleaning system, with subsequent layer wetting, probable layer swelling, weakening and complete or partial detachment, as observed by visual inspection. A stronger limewash adhesion on the hydrophilic fresco surface than on tempera was observed. Calcium extraction from the substrate, though in small degree, also occurs.

The action of all the cleaning materials used on limewash resulted not harmful to the integrity of the hematite layer underneath.

A small damage in terms of extracted iron was detected for all the cleaning systems after direct contact with fresco and tempera hematite layers. However, the organic binder of tempera displayed a greater "protective" effect for the pigment, mainly exerted through the lipidic component present in the yolk. The sensitivity of pigments to chelating agents when bound in different media is here evidenced for the first time.

Cleaning materials with additives extract metal ions more efficiently than pure materials, with a greater coordinating ability 
for EDTA than for TAC, increasing with their percentage. Structure differences between gels and pulps lead to a different interaction strength with the underlying fresco and tempera layers, which deserves to be further investigated in future research. Data suggest a more efficient backward transportation of aqueous solutions containing metal ions towards gels with respect to cellulose.

Operatively, for the cleaning of wall paintings with hematite and limewash layers, a good compromise can be pursued between effectiveness and potential damage. For fresco painting layers, pure gel can be proposed as a good cleaning material, since it allows both a good limewash removal and a lack of iron extraction from the painting layers. Cellulose pulp, both pure and additivated, also extracts no iron, but it is not completely effective for limewash removal. Instead limewash removal and a negligible iron extraction were observed after contact with pure gel, gel additivated with TAC and pure cellulose on tempera layers.

The investigation methods adopted in this study are of general interest, since they allow to evaluate effectiveness and damage whenever procedures require layer removal and/or metal-based pigment cleaning, thus giving useful suggestions for the planning of repeated cleaning operations on a real polychrome object.

\section{References}

[1] V. Vergès-Belmin, Towards a definition of common evaluation criteria for the cleaning of porous building materials: a review, Sci. Technol. Cult. Herit. 5 (1996) 69-83.

[2] A.M. Mecchi, T. Poli, M. Realini, A. Sansonetti, A proposal for a common approach in choosing tests for the protocol evaluation of cleaning methods, in: 11 th Int. Congr. Deterior. Conserv. Stone., Wydawnictwo Naukowe PWN, Torun, 2008, 2021, pp. 425-433.

[3] V.E. Selva Bonino, M. Tegoni, C. Mucchino, G. Predieri, A. Casoli, Model study of the constituents of wall painting degradation patinas: The effect of the treatment with chelating agents on the solubility of the calcium salts, Microchem. J. 118 (2015) 62-68, doi:10.1016/j.microc.2014.08.001.

[4] J. Watt, J. Tidblad, V. Kucera, R. Hamilton, The Effects of Air Pollution on Cultural Heritage, Springer US, 2009.

[5] J. Striova, M. Camaiti, E.M. Castellucci, A. Sansonetti, Chemical, morphological and chromatic behavior of mural paintings under Er:YAG laser irradiation, Appl. Phys. A. 104 (2011) 649-660, doi:10.1007/s00339-011-6303-6.

[6] M. Bertasa, C. Canevali, A. Sansonetti, M. Lazzari, M. Malandrino, R. Simonutti, D. Scalarone, An in-depth study on the agar gel effectiveness for built heritage cleaning, J. Cult. Herit. 47 (2021) 12-20, doi:10.1016/j.culher.2020.10.007.

[7] F. Mancini, V. Ruppen, S. Cerea, E. Isella, D. Bonelli, A. Botteon, A. Sansonetti, Confronto di metodi di descialbo con diverse sorgenti laser, in: APLAR 6, Nardini Editore, 2019, pp. 111-124.

[8] D. Slaton, K.C. Normandin, Masonry Cleaning Technologies, J. Archit. Conserv. 11 (2005) 7-31, doi:10.1080/13556207.2005.10784950.

[9] V. Vergès-Belmin, A. Heritage, A. Bourgès, Powdered Cellulose Poultices in Stone and Wall Painting Conservation - Myths and Realities, Stud. Conserv. 56 (2011) 281-297, doi:10.1179/204705811X13159282692923.

[10] E. De Witte, M. Dupas, Cleaning poultices based on EDTA, in: Proc. 7th Int. Congr. Deterior. Conserv. Stone Held Lisbon, Port. 15-18 June 1992, 1992, pp. 1023-1031.

[11] P. Baglioni, D. Berti, M. Bonini, E. Carretti, L. Dei, E. Fratini, R. Giorgi, Micelle, microemulsions, and gels for the conservation of cultural heritage, Adv. Colloid Interface Sci. 205 (2014) 361-371, doi:10.1016/j.cis.2013.09.008.

[12] A. Heritage, A. Heritage (Eds.), Desalination of Historic Buildings Stone and Wall PaintingsArchetype, London, 2013 Eds.

[13] R. Mastrangelo, C. Montis, N. Bonelli, P. Tempesti, P. Baglioni, Surface cleaning of artworks: structure and dynamics of nanostructured fluids confined in polymeric hydrogel networks, Phys. Chem. Chem. Phys. 19 (2017) 23762-23772, doi:10.1039/C7CP02662E.

[14] D. Chelazzi, E. Fratini, R. Giorgi, R. Mastrangelo, M. Rossi, P. Baglioni, Gels for the Cleaning of Works of Art, in: Gels Other Soft Amorph. Solids, American Chemical Society, 2018, 2021, pp. 291-314, doi:10.1021/bk-2018-1296.ch015.

[15] D. Chelazzi, R. Giorgi, P. Baglioni, Micelles Microemulsions, Functional Gels, How Colloids and Soft Matter Preserve Works of Art, Angew. Chemie Int. Ed. 57 (2018) 7296-7303, doi:10.1002/anie.201710711.

[16] N. Bonelli, G. Poggi, D. Chelazzi, R. Giorgi, P. Baglioni, Poly(vinyl alcohol)/poly(vinyl pyrrolidone) hydrogels for the cleaning of art, J. Colloid Interface Sci. 536 (2019) 339-348, doi:10.1016/j.jcis.2018.10.025.

[17] M. Bertasa, O. Chiantore, T. Poli, C. Riedo, V. di Tullio, C. Canevali, A. Sansonetti, D. Scalarone, A Study of Commercial Agar Gels as Cleaning Materials, Gels Conserv. Art (2017) 11-18.

[18] A. Sansonetti, M. Casati, J. Striova, C. Canevali, M. Anzani, A. Rabbolini, A Cleaning Method Based on the use of Agar Gels: New Tests and Perspectives, in: G. Wheeler (Ed.), 12th Int. Congr. Deterior. Conserv. Stone, Columbia Univ., 2012, 2021, pp. 1-13.
[19] M. Bertasa, A. Dodero, M. Alloisio, S. Vicini, C. Riedo, A. Sansonetti, D. Scalarone, M. Castellano, Agar gel strength: A correlation study between chemical composition and rheological properties, Eur. Polym. J. 123 (2020) 109442, doi:10.1016/j.eurpolymj.2019.109442.

[20] A. Sansonetti, M. Bertasa, C. Canevali, A. Rabbolini, M. Anzani, D. Scalarone, A review in using agar gels for cleaning art surfaces, J. Cult. Herit. 44 (2020) 285-296, doi:10.1016/j.culher.2020.01.008.

[21] L.V Angelova, B. Ormsby, J. Townsend, R. Wolbers, Gels in the Conservation of Art, Archetype Publications, London, 2017.

[22] C. Mazzuca, L. Micheli, M. Carbone, F. Basoli, E. Cervelli, S. Iannuccelli, S. Sotgiu, A. Palleschi, Gellan hydrogel as a powerful tool in paper cleaning process: A detailed study, J. Colloid Interface Sci. 416 (2014) 205-211, doi:10.1016/j.jcis. 2013.10.062.

[23] A. Casoli, P. Cremonesi, C. Isca, R. Groppetti, S. Pini, N. Senin, Evaluation of the effect of cleaning on the morphological properties of ancient paper surface, Cellulose 20 (2013) 2027-2043, doi:10.1007/s10570-013-9975-6.

[24] M. Bertasa, F. Bandini, A. Felici, M.R. Lanfranchi, R. Negrotti, C. Riminesi, D. Scalarone, A. Sansonetti, Soluble Salts Extraction with Different Thickeners: Monitoring of the Effects on Plaster, IOP Conf. Ser. Mater. Sci. Eng. 364 (2018) 012076, doi:10.1088/1757-899X/364/1/012076.

[25] S. Prati, F. Volpi, R. Fontana, P. Galletti, L. Giorgini, R. Mazzeo, L. Mazzocchetti, C. Samorì, G. Sciutto, E. Tagliavini, Sustainability in art conservation: a novel bio-based organogel for the cleaning of water sensitive works of art, Pure Appl. Chem. 90 (2018) 239-251, doi:10.1515/pac-2017-0507.

[26] R. Abd-Allah, Chemical cleaning of soiled deposits and encrustations on archaeological glass: A diagnostic and practical study, J. Cult. Herit. 14 (2013) 97-108, doi:10.1016/j.culher.2012.03.010.

[27] S. Spile, T. Suzuki, J. Bendix, K.P. Simonsen, Effective cleaning of rust stained marble, Herit. Sci. 4 (2016) 12, doi:10.1186/s40494-016-0081-6.

[28] C. Canevali, M. Fasoli, M. Bertasa, A. Botteon, A. Colombo, V. Di Tullio, D. Capitani, N. Proietti, D. Scalarone, A. Sansonetti, A multi-analytical approach for the study of copper stain removal by agar gels, Microchem. J. 129 (2016) 249-258, doi:10.1016/j.microc.2016.07.007.

[29] M.Á. Martínez-Domingo, A.I.Calero Castillo, E. Vivar García, E.M. Valero, Evaluation of Cleaning Processes Using Colorimetric and Spectral Data for the Removal of Layers of Limewash from Medieval Plasterwork, Sensors 20 (2020) 7147, doi:10.3390/s20247147.

[30] C. Cennini, Il libro dell'arte - The Craftsman's Handbook, Dover Publications, New York, 1933.

[31] L. Rampazzi, Calcium oxalate films on works of art: A review, J. Cult. Herit. 40 (2019) 195-214, doi:10.1016/j.culher.2019.03.002.

[32] D. Monticelli, A. Castelletti, D. Civati, S. Recchia, C. Dossi, How to Efficiently Produce Ultrapure Acids, Int. J. Anal. Chem. (2019) 1-5, doi:10.1155/2019/ 5180610.

[33] R. Bugini, C. Corti, L. Folli, L. Rampazzi, Unveiling the Use of Creta in Roman Plasters: Analysis of Clay Wall Paintings From Brixia (Italy), Archaeometry 59 (2017) 84-95, doi:10.1111/arcm.12254

[34] G. Ranalli, E. Zanardini, A. Andreotti, M.P. Colombini, C. Corti, P. Bosch-Roig, P. De Nuntiis, G. Lustrato, P. Mandrioli, L. Rampazzi, C. Giantomassi, D. Zari, Hitech restoration by two-steps biocleaning process of Triumph of Death fresco at the Camposanto Monumental Cemetery (Pisa, Italy), J. Appl. Microbiol. 125 (2018) 800-812, doi:10.1111/jam.13913.

[35] G. Ranalli, E. Zanardini, L. Rampazzi, C. Corti, A. Andreotti, M.P. Colombini, P. Bosch-Roig, G. Lustrato, C. Giantomassi, D. Zari, P. Virilli, Onsite advanced biocleaning system for historical wall paintings using new agar-gauze bacteria gel, J. Appl. Microbiol. 126 (2019) 1785-1796, doi:10.1111/jam.14275.

[36] R.J. Meilunas, J.G. Bentsen, A. Steinberg, Analysis of aged paint binders by FTIR spectroscopy, Stud. Conserv. 35 (1990) 33-51, doi:10.1179/sic.1990.35.1.33.

[37] L. Rampazzi, A. Andreotti, M. Bressan, M.P. Colombini, C. Corti, O. Cuzman, N. D’Alessandro, L. Liberatore, L. Palombi, V. Raimondi, B. Sacchi, P. Tiano, L. Tonucci, S. Vettori, E. Zanardini, G. Ranalli, An interdisciplinary approach to a knowledge-based restoration: The dark alteration on Matera Cathedral (Italy), Appl. Surf. Sci. 458 (2018) 529-539, doi:10.1016/j.apsusc.2018.07.101.

[38] R.M. Smith, A.E. Martell, R.J. Motekaitis, NIST Critically selected stability constants of metal complexes database, Gaithersburg, 2007.

[39] A.E. Martell, R.M. Smith, Critical Stability Constants, Vols. 1-4, Plenum Press, New York, 1976.

[40] T.B. Field, J.L. McCourt, W.A.E. McBryde, Composition and Stability of Iron and Copper Citrate Complexes in Aqueous Solution, Can. J. Chem. 52 (1974) 31193124, doi:10.1139/v74-458.

[41] K.S. Kang, G.T. Veeder, P.J. Mirrasoul, T. Kaneko, I.W. Cottrell, Agar-Like Polysaccharide Produced by a Pseudomonas Species: Production and Basic Properties, Appl. Environ. Microbiol. 43 (1982) 1086-1091, doi:10.1128/AEM.43.5. 1086-1091.1982.

[42] A. Coccato, L. Moens, P. Vandenabeele, On the stability of mediaeval inorganic pigments: a literature review of the effect of climate, material selection, biological activity, analysis and conservation treatments, Herit. Sci. 5 (2017) 12 doi:10.1186/s40494-017-0125-6.

[43] E. Borghi, M. Occhiuzzi, E. Foresti, I.G. Lesci, N. Roveri, Spectroscopic characterization of Fe-doped synthetic chrysotile by EPR, DRS and magnetic susceptibility measurements, Phys. Chem. Chem. Phys. 12 (2010) 227-238, doi:10.1039/ B915182F. 